Research Article

\title{
Pattern Recognition of Signals for the Fault-Slip Type of Rock Burst in Coal Mines
}

\author{
X. S. Liu, ${ }^{1}$ J. Tan, ${ }^{1,2}$ Y. L. Tan, ${ }^{1}$ and S. C. Hu ${ }^{1}$ \\ ${ }^{1}$ State Key Laboratory of Mining Disaster Prevention and Control Co-Founded by Shandong Province and the Ministry of \\ Science and Technology, Shandong University of Science and Technology, Qingdao 266590, China \\ ${ }^{2}$ College of Engineering, Western New England University, Springfield, MA 01119, USA \\ Correspondence should be addressed to J. Tan; tjtylllp@126.com
}

Received 25 May 2015; Revised 16 July 2015; Accepted 21 July 2015

Academic Editor: Farhang Daneshmand

Copyright (C) 2015 X. S. Liu et al. This is an open access article distributed under the Creative Commons Attribution License, which permits unrestricted use, distribution, and reproduction in any medium, provided the original work is properly cited.

\begin{abstract}
The fault-slip type of rock burst is a major threat to the safety of coal mining, and effectively recognizing its signals patterns is the foundation for the early warning and prevention. At first, a mechanical model of the fault-slip was established and the mechanism of the rock burst induced by the fault-slip was revealed. Then, the patterns of the electromagnetic radiation, acoustic emission (AE), and microseismic signals in the fault-slip type of rock burst were proposed, in that before the rock burst occurs, the electromagnetic radiation intensity near the sliding surface increases rapidly, the AE energy rises exponentially, and the energy released by microseismic events experiences at least one peak and is close to the next peak. At last, in situ investigations were performed at number 1412 coal face in the Huafeng Mine, China. Results showed that the signals patterns proposed are in good agreement with the process of the fault-slip type of rock burst. The pattern recognition can provide a basis for the early warning and the implementation of relief measures of the fault-slip type of rock burst.
\end{abstract}

\section{Introduction}

The fault-slip type of rock burst is one of the main types of rock burst in coal mines, and it is a great threat to the mining safety due to its devastation and the large amount of coal extruded $[1,2]$. Effectively recognizing the signals patterns of the fault-slip type of rock burst not only is the prerequisite for its early warning, but also plays a great role in the implementation of relief measures [3-7].

Many researchers have made contributions to the monitoring and early warning of rock burst and proposed many kinds of monitoring approaches (e.g., electromagnetic radiation, AE, microseismic signals, and stress) [8-16]. The electromagnetic radiation monitoring is an approach that obtains the stress magnitude and variations of coal and rock by monitoring the intensity and pulse of electromagnetic radiation [8]. Song et al. and Liu et al. investigated the approach to estimate the rock burst danger from the intensity and pulse of electromagnetic radiation and proposed an early warning criterion $[9,10]$. AE is accompanied by the damage of microcracks in rocks [11]. The damage evolution of rocks can be obtained by monitoring the AE energy and frequency. Tan et al. and Ji et al. proposed the patterns of AE signals based on two particular geological conditions, respectively $[12,13]$. Microseismic monitoring is an approach to determine the failure degree of rocks by analyzing the energies, frequencies, and wavelengths of microseismic events gathered by demodulators. Jiang et al. investigated the features of microseismic signals during the process of rock burst and proposed some early warning criterions [14]. All these approaches play important roles for the early warning of rock burst and lay the foundation for its prevention. In particular, they can accurately forecast the strain type of rock burst induced by the mining abutment pressure, which improves the mining safety effectively.

Although the fault-slip type of rock burst is greatly influenced by the mining abutment pressure, it is different from the strain type of rock burst. In fact, the root of the fault-slip type of rock burst is the relative slipping of fault walls [17-19]. Therefore, the existing recognition approaches 


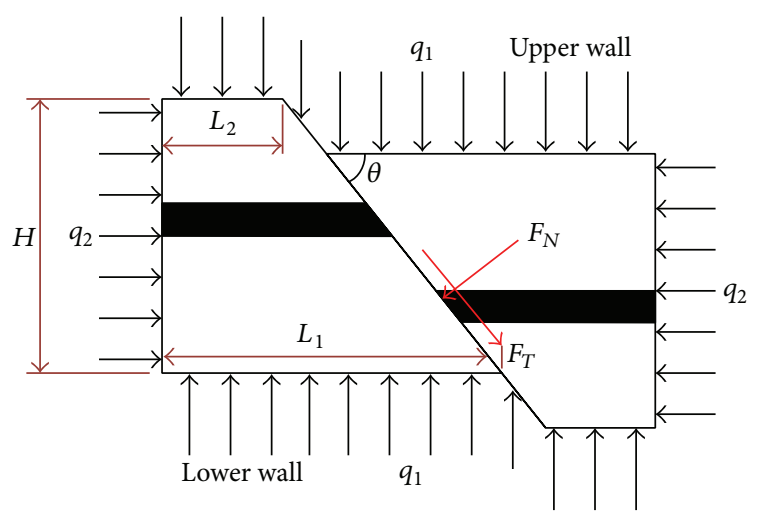

FIgURE 1: Mechanical model of the fault-slip.

of signals patterns for rock burst cannot apply to the faultslip type of rock burst $[20,21]$. For this reason, this paper first established a mechanical model of the fault-slip and analyzed the mechanism of the rock burst induced by the faultslip. We then proposed the recognition approaches of the electromagnetic radiation, AE, and microseismic signals for the fault-slip type of rock burst. Finally, in situ investigations were presented to demonstrate the validity of the approaches.

\section{Pattern Recognition of Signals}

2.1. Mechanical Rationale. Influenced by the geological changes and tectonic activities, there are many geological formations in coal-bearing strata. Usually, large build-up of elastic strain energy occurs near the geological formations. The forces in coal and rock are in an equilibrium state without mining activities. Taking a single normal fault as an example, the mechanical model of the fault-slip is shown in Figure 1. It shows the forces on the two fault walls around the fault sliding surface.

Uninfluenced by mining activities, the fault walls are in stable state and do not move. According to the force balance of the lower wall, the shear force, $F_{T}$, and the normal force, $F_{N}$, at the sliding surface can be expressed, respectively, as

$$
\begin{aligned}
& F_{T}=q_{1} \sin \theta\left(L_{1}-L_{2}\right)-q_{2} H \cos \theta \\
& F_{N}=q_{1} \cos \theta\left(L_{1}-L_{2}\right)+q_{2} H \sin \theta,
\end{aligned}
$$

where $q_{1}$ is vertical stress loaded on the top and bottom of the fault, $q_{2}$ is the horizontal stress loaded on the sides of the fault, $L_{1}$ is the length of the downside of the lower wall, $L_{2}$ is the length of the upside of the lower wall, and $H$ is the height of the lower wall.

Considering the geometrical relationship

$$
\tan \theta=\frac{L_{1}-L_{2}}{H},
$$

then the shear stress, $\sigma$, and the normal stress, $\tau_{T}$, at the sliding surface were calculated, respectively, as

$$
\begin{aligned}
\sigma & =q_{1} \sin ^{2} \theta+q_{2} \sin ^{2} \theta \\
\tau_{T} & =q_{1} \sin ^{2} \theta \tan \theta-q_{2} \sin \theta \cos \theta .
\end{aligned}
$$

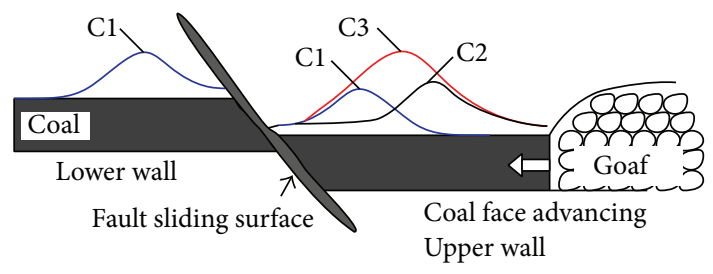

FIGURE 2: The cross section of a normal fault and abutment distribution: $\mathrm{C} 1$ is the preexisting tectonic pressure curve; $\mathrm{C} 2$ is the mining abutment pressure curve; and $\mathrm{C} 3$ is the superimposed pressure curve.

The shear strength of the sliding surface can be obtained as [22]

$$
\tau=c+q_{1} \sin ^{2} \theta \tan \varphi+q_{2} \sin ^{2} \theta \tan \varphi,
$$

where $c$ is the cohesion and $\varphi$ is the friction angle.

If the shear stress at the sliding surface is larger than its shear strength, the fault walls will slip relatively, and vice versa. Thus, the slipping criterion of the fault walls is

$$
\tau_{T} \begin{cases}\leq \tau & \text { no fault-slip occurs } \\ >\tau & \text { the fault-slip occurs }\end{cases}
$$

Without any mining activities, no rock burst occurs for the fault walls do not slip relatively. According to (7), the shear stress at the sliding surface is less than its shear strength in this condition. Influenced by mining activities, the vertical stress, $q_{1}$, and the horizontal stress, $q_{2}$, may change. So both values of the shear stress at the sliding surface and the shear strength change. In the condition that the shear stress at the sliding surface is smaller than its shear strength, the fault walls do not slip relatively and no rock burst occurs. However, if the shear stress at the sliding surface is larger than its shear strength, the fault walls will slip relatively. Once the slipping begins, it will accelerate for the static friction converts to the dynamical friction, which will result in rock burst.

For example, when the coal face moves from the upper wall to the normal fault, the abutment pressure distribution is shown in Figure 2. The curves $\mathrm{C} 1$ and $\mathrm{C} 2$ present the distribution of the preexisting tectonic pressure and the mining abutment pressure, respectively. During the coal face closing to the fault, the preexisting tectonic pressure and the mining abutment pressure superimpose; see curve C3 in Figure 2. Part of the front coals will fail due to the high superimposed pressure, which results in lower supporting force to the upper rocks. In this condition, the shear stress at the sliding surface will increase. When it is larger than the shear strength, a fault-slip type of rock burst will occur.

2.2. Recognition Approaches. Before the fault-slip occurs, the rough sliding surface will be smoothed under high stress, with accompanying failure of coals and rocks. Therefore, whether the fault-slip type of rock burst will occur or not can 


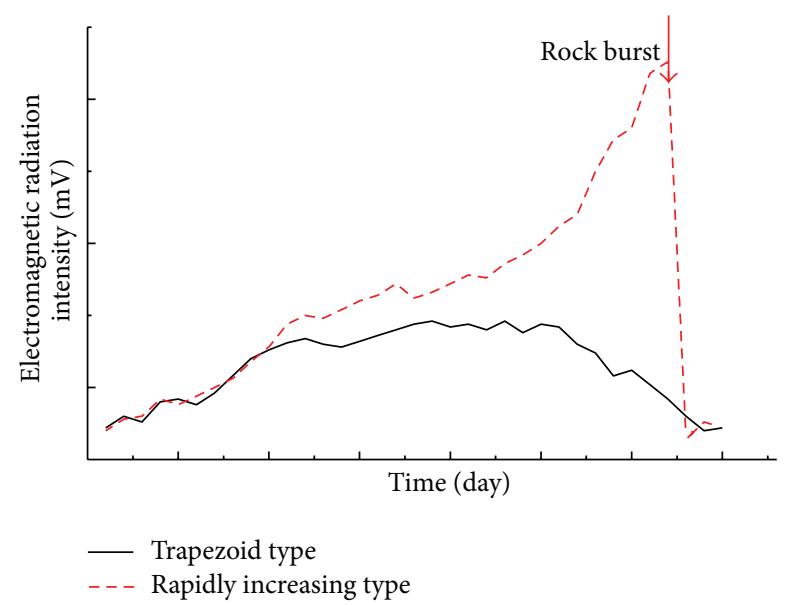

FIgURE 3: Patterns of the electromagnetic radiation intensity with the closing of the coal face to the fault.

be determined by recognizing the patterns of stress, energy, and failure degree of coal and rock near the sliding surface.

(1) Patterns of the Electromagnetic Radiation Intensity. Studies show that the danger of rock burst increases with the concentration degree of stress in coal and rock $[4,17]$. And the strength of the electromagnetic radiation signals is positively related to the stress state of rock. Therefore, we can determine the danger of the fault-slip type of rock burst from the variations of the electromagnetic radiation signals near the sliding surface. With the closing of the coal face to the fault, the variations of the electromagnetic radiation intensity are shown in Figure 3.

The coal face is approaching the fault. Hence, the electromagnetic radiation intensity near the sliding surface begins to increase for the rocks are loaded by both the preexisting tectonic pressure and the mining abutment pressure. Since the coal face continues advancing to the fault, if the electromagnetic radiation intensity is maintained at a high level for a long time and then decreases slowly (see the trapezoid type in Figure 3), no rock burst will occur. In this condition, the high concentrated stress moves to the area farther away from the fault. However, if the high concentrated stress does not move away, the electromagnetic radiation intensity near the sliding surface will increase rapidly (see the rapidly increasing type in Figure 3). In this condition, there is a high risk of the faultslip type of rock burst because large build-up of elastic strain energy occurs near the sliding surface.

(2) Patterns of the AE Energy. During the rock mass damage and failure processes, the stored energy is dissipated and released in the form of $\mathrm{AE}$ and microseismic event. The accumulation of $\mathrm{AE}$ is a direct reflection of the damage in rocks, and we can estimate the rock mass stability by analyzing the $\mathrm{AE}$ frequency and energy in a particular area [12]. Experiments show that the AE frequency and energy increase exponentially while the loading stress is close to its



FIGURE 4: Patterns of AE energy with the closing of the coal face to the fault.

strength and reaches the maximum at the strength [23]. With the closing of the coal face to the fault, the variations of the AE energy are shown in Figure 4.

The AE energy near the sliding surface rises because the rock flaws extend and merge under the superimposed pressure when the coal face is close to the fault. As the coal face continues advancing to the fault, if the AE energy is maintained at a high level for a long time and then decreases slowly (see the trapezoid type in Figure 4), no rock burst will occur. In this condition, the high concentrated stress moves to the area farther away from the fault. However, if the AE energy near the sliding surface rises exponentially (see the exponentially rising type in Figure 4), this is highly dangerous. In this condition, a large amount of elastic strain energy is accumulated near the sliding surface for the high concentrated stress does not move away, and the fault-slip type of rock burst is very likely to happen.

(3) Patterns of the Microseismic Signal. Comparing with AE, microseismic signal is another kind of wave with higher energy and lower frequency. It is accompanied by rock ruptures, with the energy ranging from $10^{2}$ to $10^{5} \mathrm{~J}$ and the frequency less than $150 \mathrm{~Hz}$ [14]. By analyzing the microseismic data in a particular area, we can determine the failure degree of rocks. With the closing of the coal face to the fault, the variations of the energy released by microseismic events are shown in Figure 5.

The coal face is approaching the fault. Hence, the energy released by microseismic events near the sliding surface increases because both the microseismic energy and frequency increase due to the larger amount of rock ruptures. Since the coal face continues advancing to the fault, if the released energy is maintained at a high level for a long time and then decreases slowly (see the trapezoid type in Figure 5), no rock burst will occur. In this condition, the high concentrated stress moves to the area farther away from the 
TABLE 1: Lithology description.

\begin{tabular}{|c|c|c|c|c|}
\hline Sequence & Appellation & Thickness (m) & Symbol & Description \\
\hline \multirow{3}{*}{1} & \multirow{3}{*}{ Siltstone } & \multirow{3}{*}{10.4} & $\bullet \bullet \bullet \bullet \bullet \bullet$ & \multirow{3}{*}{$\begin{array}{l}\text { Grey black, medium- } \\
\text { and thick-bedded }\end{array}$} \\
\hline & & & $\bullet \bullet \bullet \bullet \bullet \bullet$ & \\
\hline & & & $\bullet \bullet \bullet \bullet \bullet \bullet$ & \\
\hline \multirow{4}{*}{2} & \multirow{4}{*}{ Fine sandstone } & \multirow{4}{*}{12.6} & $\bullet \bullet \bullet$ & \multirow{4}{*}{$\begin{array}{l}\text { Grey black, siliceous } \\
\text { cement and dense }\end{array}$} \\
\hline & & & $\bullet \bullet \bullet$ & \\
\hline & & & - $\bullet \bullet$ & \\
\hline & & & - $\bullet \bullet$ & \\
\hline \multirow[t]{2}{*}{3} & Gritstone & 7.9 & 0 & $\begin{array}{l}\text { Grey, sandy structure } \\
\text { and well sorted. }\end{array}$ \\
\hline & \multirow{3}{*}{ Sandy mudstone } & \multirow{3}{*}{5.8} & $=-0$ & \multirow{3}{*}{$\begin{array}{l}\text { Hard coal core and } \\
\text { sandy evenly } \\
\text { distributed. }\end{array}$} \\
\hline \multirow[t]{2}{*}{4} & & & $0-\square$ & \\
\hline & & & --0 & \\
\hline 5 & Number 4 seam & 6.2 & & $\begin{array}{l}\text { Semibright with } \\
\text { simple structure. }\end{array}$ \\
\hline
\end{tabular}

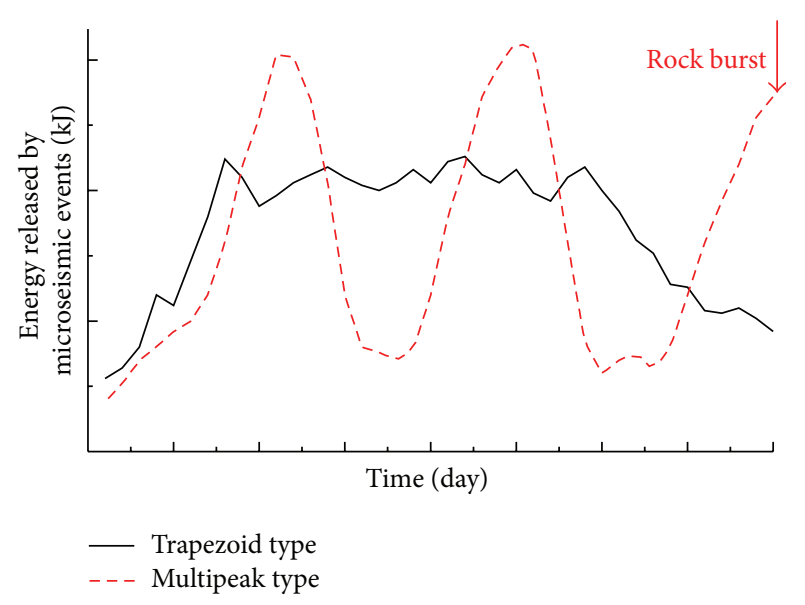

FIGURE 5: Patterns of the energy released by microseismic events with the closing of the coal face to the fault.

fault. However, if the released energy experiences multiple peaks and is close to the next peak (see the multipeak type in Figure 5), there is a high risk of the fault-slip type of rock burst. In this condition, the high concentrated stress does not move away and large build-up of elastic strain energy occurs near the sliding surface because there is very small energy released between two adjacent peaks.

\section{Cases Investigations}

3.1. Geological Conditions. The trial work was conducted at number 1412 coal face in the Huafeng Mine, Shandong Province, China. The coal seam is simple in geological formation. The buried depth of the coal seam is from 1083.5 to $1215.8 \mathrm{~m}$, with an average of $1170 \mathrm{~m}$. The thickness of the coal seam ranges from 5.5 to $6.9 \mathrm{~m}$, with an average of $6.2 \mathrm{~m}$. The dip angle is from 30 to $34^{\circ}$. The immediate roof is $5.8 \mathrm{~m}$ thick sandy mudstone and $7.9 \mathrm{~m}$ thick gritstone. The basic roof is $12.6 \mathrm{~m}$ thick fine sandstone and $10.4 \mathrm{~m}$ thick siltstone, as shown in Table 1.

The strike length and the incline length of the coal face are 2190 and $143 \mathrm{~m}$, respectively. The longwall top-coal caving mining technology is used and the coal face advances $12 \mathrm{~m}$ per day. There is a normal fault named F18 crossing the face, about 1052.7 to $1198.6 \mathrm{~m}$ away from the open-off, with the dip angle of $62^{\circ}$ and the throw of $8.5 \mathrm{~m}$, as shown in Figure 6.

The average compressive strength of coal is approximately 19.58 $\mathrm{MPa}$. The immediate roof is siltstone and sandstone with the average thickness of $19.3 \mathrm{~m}$, and its average compressive strength is of $69.26 \mathrm{MPa}$. The main roof is siltstone and fine sandstone with the average thickness of $38.2 \mathrm{~m}$, and its average compressive strength is of $102.8 \mathrm{MPa}$. Both the coal and the roof strata show some burst trend.

3.2. Monitoring Schemes. The monitoring work was conducted from July to December 2014. An electromagnetic 




FIGURE 6: Number 1412 coal face and station layout.

radiation monitoring instrument (KBD5, Xuzhou Fuan Technology Co., Ltd.), an AE monitoring system (KJ623, Uroica Mining Safety Engineering Co., Ltd.), and a microseismic monitoring system (KJ551, Beijing Anke Technology Co., Ltd.) were used as the monitoring devices, as demonstrated by Figure 7. There were two surveying stations, Station I and Station II, as shown in Figure 6. In each station, there were six measuring points of the electromagnetic radiation monitoring instrument with the spacing of $10 \mathrm{~m}$, four $\mathrm{AE}$ sensors with the spacing of $30 \mathrm{~m}$, and four demodulators of the microseismic monitoring system with the spacing of $50 \mathrm{~m}$. The AE sensor was mounted at the end of a special cable that was $2000 \mathrm{~mm}$ in the coal wall, as shown in Figure 7(c). The demodulator was installed in the roof at the depth of $18 \mathrm{~m}$ by a drill hole with the diameter of $58 \mathrm{~mm}$. The electromagnetic radiation signal was monitored and recorded manually every four hours. And the signals of $\mathrm{AE}$ and microseismic event were in real-time monitored with all the data stored simultaneously.

\section{Results and Discussions}

4.1. Results. The monitoring results were shown in Figure 8. As shown in Figure 8(a), the electromagnetic radiation intensity was about $50 \mathrm{mV}$ before September 25 and increased to about $105 \mathrm{mV}$ between September 25 and October 8. Then, the electromagnetic radiation intensity began to increase rapidly and reached about $400 \mathrm{mV}$ on October 18, nearly eight times larger than that of the beginning. After that, the electromagnetic radiation intensity decreased suddenly and remained at about $45 \mathrm{mV}$. As shown in Figure 8(b), the AE energy was really small before September 27 and experienced an exponential rising between September 27 and October 19. Then, the AE energy reduced rapidly to the initial level. As shown in Figure 8(c), there was no microseismic event before September 25. The number of microseismic events began to increase on September 26 and the largest number was about 70 on October 20 . The energy released by microseismic events rose to a peak of about $15.2 \mathrm{~kJ}$ on October 4 . Then, the released energy decreased to a nadir of about $2.5 \mathrm{~kJ}$ on October 7 and increased gradually to about $23.9 \mathrm{~kJ}$ on October 19 . After that, the released energy decreased rapidly and remained at about $3.8 \mathrm{~kJ}$.

A rock burst of magnitude 1.3 occurred in the coal face on October 18, which causes about 38 tons of coal thrown into the face. Compared with the variations of the electromagnetic radiation intensity, AE energy, and energy released by microseismic events as the coal face advances, the rock burst occurred after a rapidly increasing period of the electromagnetic radiation intensity, after an exponential rising period of the AE energy, and about two days before the energy released by microseismic events reached its second peak.

4.2. Discussions. Effectively recognizing the signals patterns is not only the promise of the early warning for the rock burst but also the basis for the implementation of relief measures. As one of the main types of rock burst, the fault-slip type of rock burst is a great threat to the mining safety, and it is necessary to investigate the recognition approaches of its signals patterns.

As mentioned above, the rough sliding surface is smoothed under high stress before the fault-slip occurs, accompanied by the failure of coals and rocks. Studies show that the strength of the electromagnetic radiation signal is positively related to the stress state of rocks and the signals of $\mathrm{AE}$ and microseismic event can reflect the damage and failure degree of rocks $[8,9,11-14]$. Therefore, we can determine the stress and energy states and failure degree from the variations of the electromagnetic radiation, $\mathrm{AE}$, and microseismic signals near the sliding surface, which can reflect the risk of the fault-slip type of rock burst.

During the coal face closing to the fault, the faultslip type of rock burst will happen under some conditions, for example, when the electromagnetic radiation intensity near the sliding surface increases rapidly, or the AE energy rises exponentially, and the energy released by microseismic events experiences at least one peak and is close to the next peak. In situ investigations in number 1412 coal face of the Huafeng Mine showed that the signals patterns are in good agreement with the process of the fault-slip type of rock burst. Therefore, we can give advance warning of the 


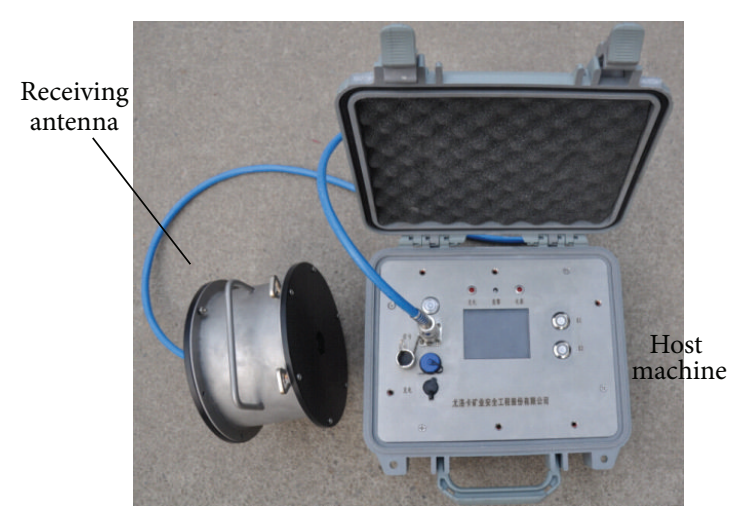

(a) KBD5 electromagnetic radiation monitoring instrument

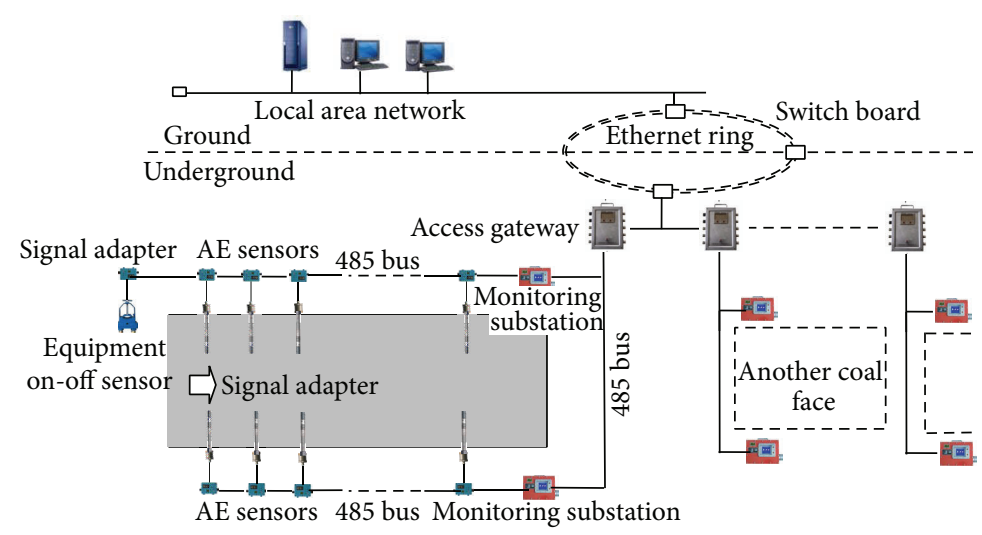

(b) KJ623 AE monitoring system

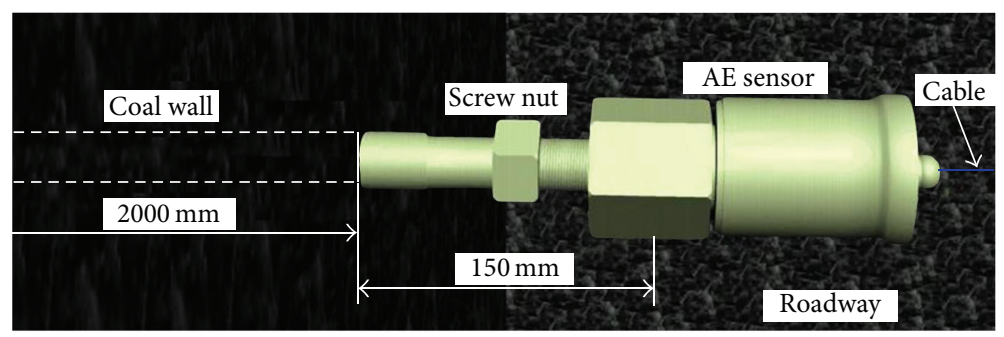

(c) Installation of AE sensor

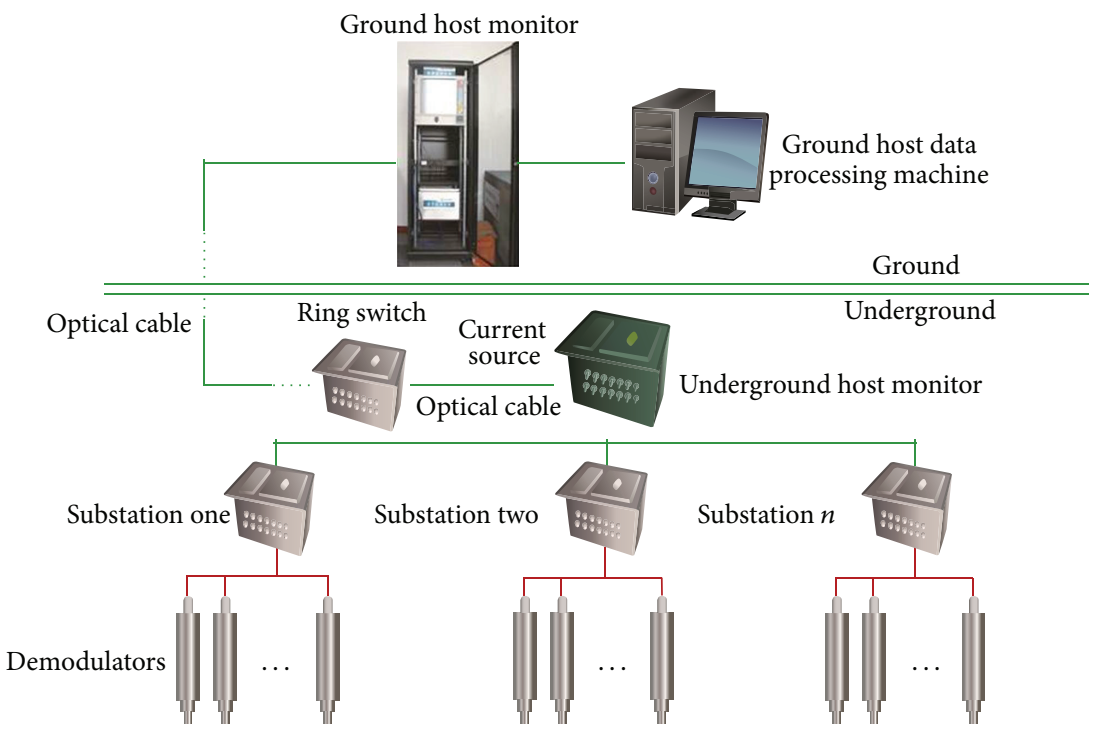

(d) KJ551 microseismic monitoring system

Figure 7: Monitoring devices.

fault-slip type of rock burst by analyzing the variations of the electromagnetic radiation, $\mathrm{AE}$, and microseismic signals, which also provides some basis for the implementation of relief measures.

\section{Conclusions}

(1) The stresses near the sliding surface are redistributed due to the mining activities. Once the shear stress at the surface is larger than its shear strength, the fault-slip will occur, which is the root of the faultslip type of rock burst. Before the fault-slip occurs, the surface will be smoothed under high stress, with accompanying failure of coals and rocks.

(2) Before the fault-slip type of rock burst occurs, the electromagnetic radiation intensity near the sliding surface increases rapidly, the AE energy rises exponentially, and the energy released by microseismic events experiences at least one peak and is close to the next peak. In situ investigations showed that 


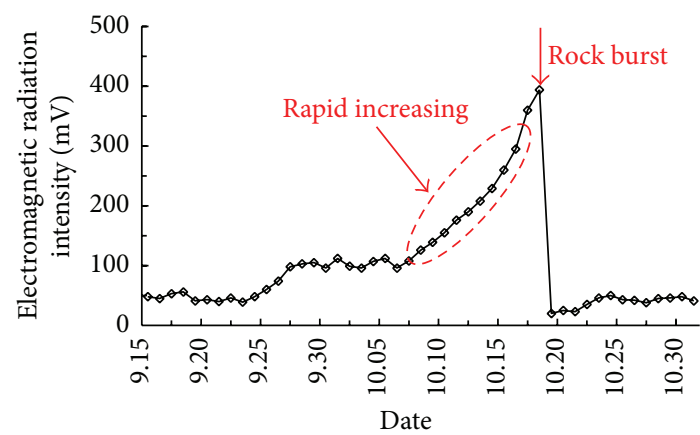

(a) The electromagnetic radiation intensity

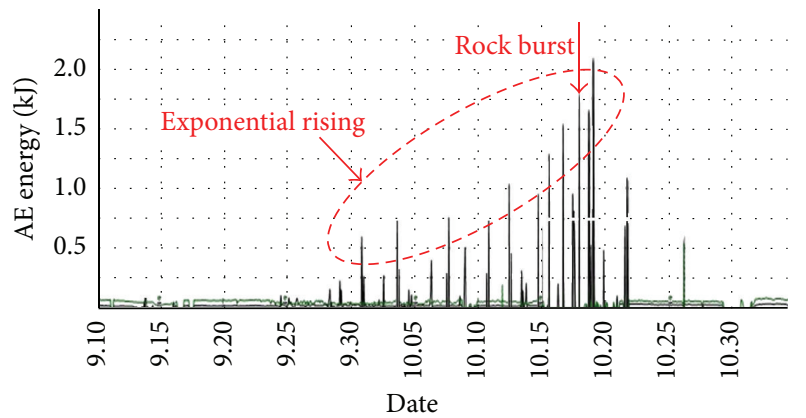

(b) The AE energy

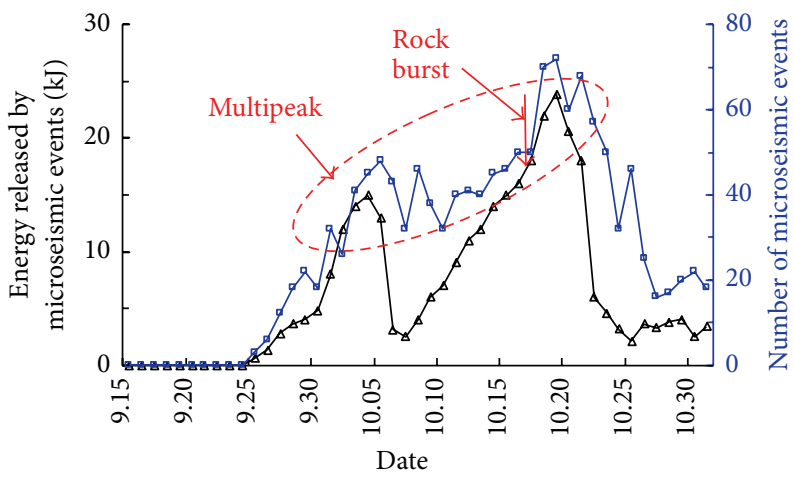

(c) The energy released by microseismic events

Figure 8: Monitoring results.

the signals patterns are in good agreement with the process of the fault-slip type of rock burst.

(3) Based on the effective recognition of the electromagnetic radiation, $\mathrm{AE}$, and microseismic signals, the early warning of the fault-slip type of rock burst can be achieved, so is the determination of the implementation of relief measures.

\section{Conflict of Interests}

The authors declare that there is no conflict of interests regarding the publication of this paper.

\section{Acknowledgments}

This study was supported by National Natural Science Foundation of China (nos. 51274133, 51174137, and 51344009), Shandong Province Natural Science Fund (no. ZR2010EEZ002), Shandong Province "Taishan Scholar" Construction Project Special Fund, Doctoral Scientific Fund Project of the Ministry of Education of China (no. 20123718110013), and Open Project of State Key Laboratory of Mining Disaster Prevention and Control Co-Founded by Shandong Province and the Ministry of Science and Technology (no. MDPC2013KF12).

\section{References}

[1] X. Chen, W.-Q. Li, and X.-Y. Yan, "Analysis on rock burst danger when fully-mechanized caving coal face passed fault with deep mining," Safety Science, vol. 50, no. 4, pp. 645-648, 2012.
[2] J.-Q. Jiang, Q.-L. Wu, and H. Qu, "Evolutionary characteristics of mining stress near the hard-thick overburden normal faults," Journal of Mining and Safety Engineering, vol. 31, no. 6, pp. 881887, 2014

[3] S. Qin, J.-Y. Cheng, and S.-J. Zhu, “The application and prospect of microseismic technique in coalmine," Procedia Environmental Sciences, vol. 12, pp. 218-224, 2014.

[4] Y. L. Tan, X.-S. Liu, J.-G. Ning, and C.-L. Tian, "Front abutment pressure concentration forecast by monitoring cable-forces in the roof," International Journal of Rock Mechanics and Mining Sciences, vol. 77, pp. 202-207, 2015.

[5] M. K. Abdul-Wahed, M. Al Heib, and G. Senfaute, "Mininginduced seismicity: seismic measurement using multiplet approach and numerical modeling," International Journal of Coal Geology, vol. 66, no. 1-2, pp. 137-147, 2006.

[6] J.-G. Ning, X.-S. Liu, and Y.-L. Tan, "Mechanism of rock-burst prevention by synergizing pressure relief and reinforcement of surrounding rocks with zonal disintegration in deep coal roadway," Disaster Advances, vol. 5, no. 4, pp. 844-850, 2012.

[7] C.-P. Lu, L.-M. Dou, B. Liu, Y.-S. Xie, and H.-S. Liu, "Microseismic low-frequency precursor effect of bursting failure of coal and rock," Journal of Applied Geophysics, vol. 79, pp. 55-63, 2012.

[8] C. Wang, J.-K. Xu, X.-X. Zhao, and M.-Y. Wei, "Fractal characteristics and its application in electromagnetic radiation signals during fracturing of coal or rock," International Journal of Mining Science and Technology, vol. 22, no. 2, pp. 255-258, 2012.

[9] D. Z. Song, E. Y. Wang, C. Wang, and F. L. Xu, "Electromagnetic radiation early warning criterion of rock burst based on statistical theory," Mining Science and Technology, vol. 20, no. 5, pp. 686-690, 2010. 
[10] G. Liu, C. Lu, H.-Y. Wang, P.-F. Liu, and Y. Liu, "Warning method of coal bursting failure danger by electromagnetic radiation," Shock and Vibration, vol. 2015, pp. 1-9, 2015.

[11] M.-C. He, J.-L. Miao, and J.-L. Feng, "Rock burst process of limestone and its acoustic emission characteristics under truetriaxial unloading conditions," International Journal of Rock Mechanics and Mining Sciences, vol. 47, no. 2, pp. 286-298, 2010.

[12] Y.-L. Tan, F.-C. Li, H. Zhou, and X.-J. Han, "Analysis on acoustic emission pattern for rock burst," Chinese Journal of Rock Mechanics and Engineering, vol. 19, no. 4, pp. 425-428, 2000.

[13] H.-G. Ji, N.-N. Mu, and Y.-Z. Zhang, "Analysis on precursory characteristics of coupled acoustic emission and pressure for rock burst events," Journal of the China Coal Society, vol. 38, no. 1, pp. 1-5, 2013.

[14] F.-X. Jiang, S.-H. Yang, Y.-H. Cheng, X.-M. Zhang, Z.-Y. Mao, and F.-J. Xu, "A study on microseismic monitoring of rock burst in coal mine," Chinese Journal of Geophysics, vol. 49, no. 5, pp. 1511-1516, 2006.

[15] W. Cai, L. Dou, A. Cao, S. Gong, and Z. Li, "Application of seismic velocity tomography in underground coal mines: a case study of Yima mining area, Henan, China," Journal of Applied Geophysics, vol. 109, pp. 140-149, 2014.

[16] S. Orzepowski and J. Butra, "Evaluation of rock-mass state in Polish copper mines through monitoring the borehole deformations," Tectonophysics, vol. 456, no. 1-2, pp. 52-61, 2008.

[17] Y.-L. Tan, Z. Zhang, and C.-L. Ma, "Rock burst disaster induced by mining abutment pressure," Disaster Advances, vol. 5, no. 4, pp. 378-382, 2012.

[18] Y. M. Song, S. P. Ma, X. B. Yang, and Y. D. Jiang, "Experimental investigation on instability transient process of fault rockburst," Chinese Journal of Rock Mechanics and Engineering, vol. 30, no. 4, pp. 812-817, 2011.

[19] P. P. Procházka, "Rock bursts due to gas explosion in deep mines based on hexagonal and boundary elements," Advances in Engineering Software, vol. 72, pp. 57-65, 2014.

[20] R. Gu and U. Ozbay, "Numerical investigation of unstable rock failure in underground mining condition," Computers and Geotechnics, vol. 63, pp. 171-182, 2015.

[21] Z.-H. Li, L.-M. Dou, C.-P. Lu, Z.-L. Mu, and A.-Y. Cao, "Study on fault induced rock bursts," Journal of China University of Mining and Technology, vol. 18, no. 3, pp. 321-326, 2008.

[22] J.-G. Ning, C.-W. Zang, Q.-H. Li, P.-S. Zhang, and J.-X. Liu, Rockmass Mechanics, China Coal Industry Publishing House, Beijing, China, 2014.

[23] J. Zuo, J.-P. Pei, J.-F. Liu, R.-D. Peng, and Y.-C. Li, "Investigation on acoustic emission behavior and its time-space evolution mechanism in failure process of coal-rock combined body," Chinese Journal of Rock Mechanics and Engineering, vol. 30, no. 8, pp. 1564-1570, 2011. 

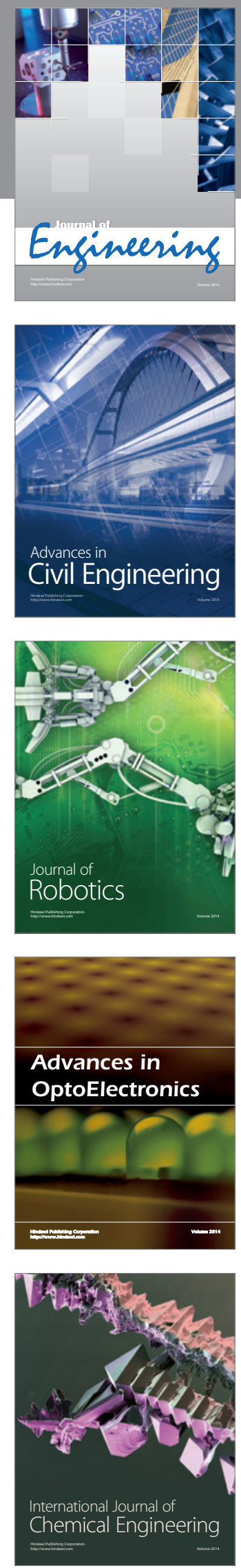

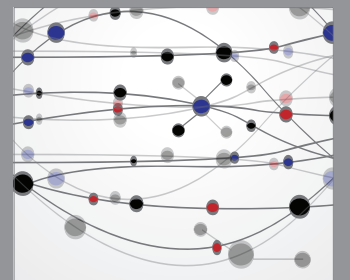

The Scientific World Journal
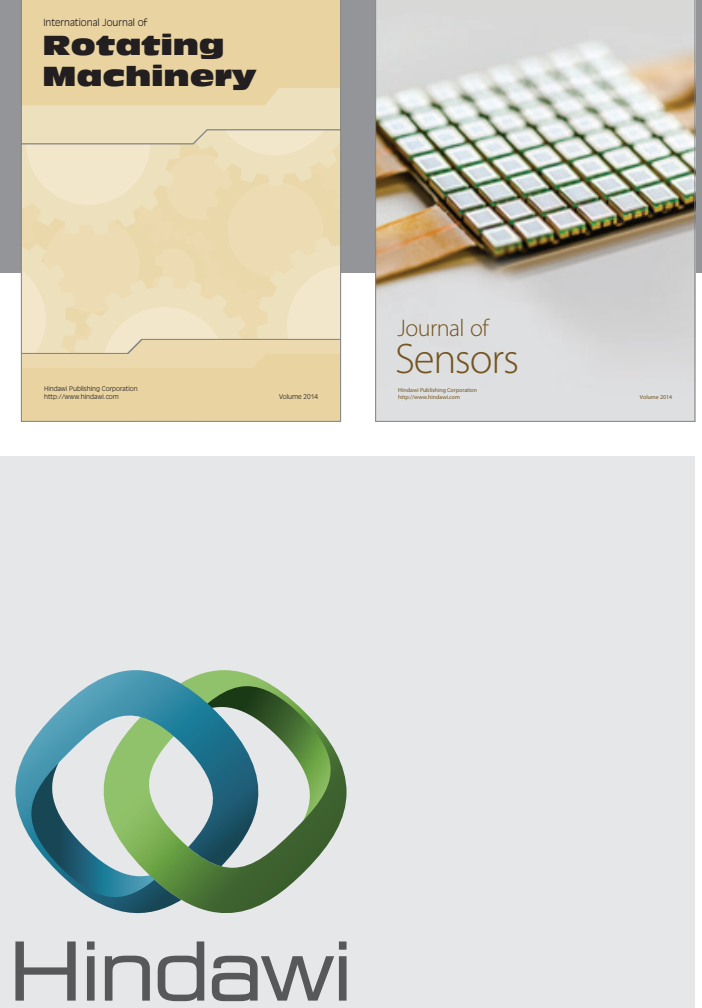

Submit your manuscripts at http://www.hindawi.com
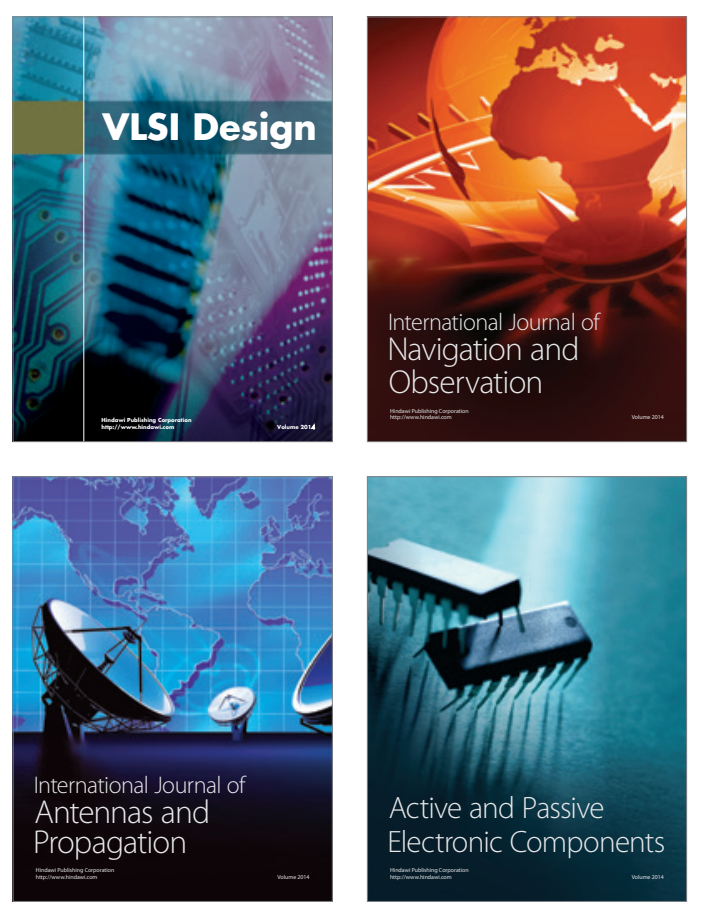
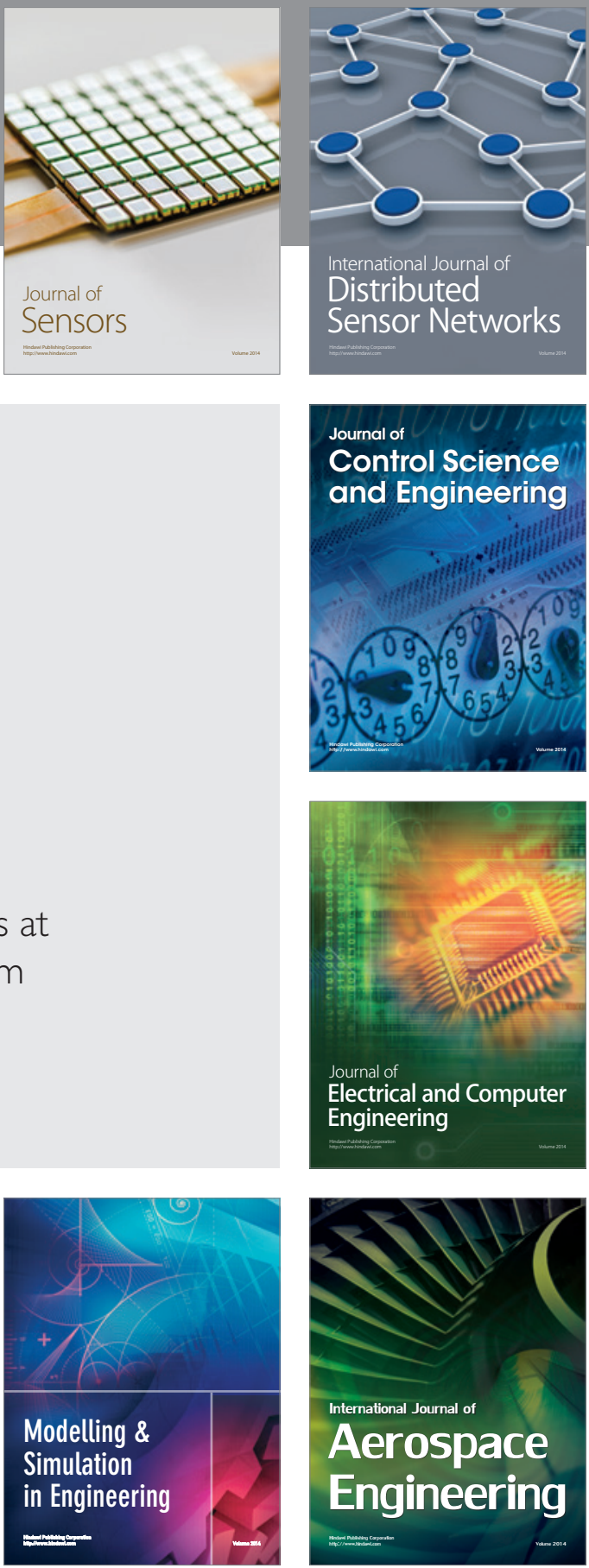

Journal of

Control Science

and Engineering
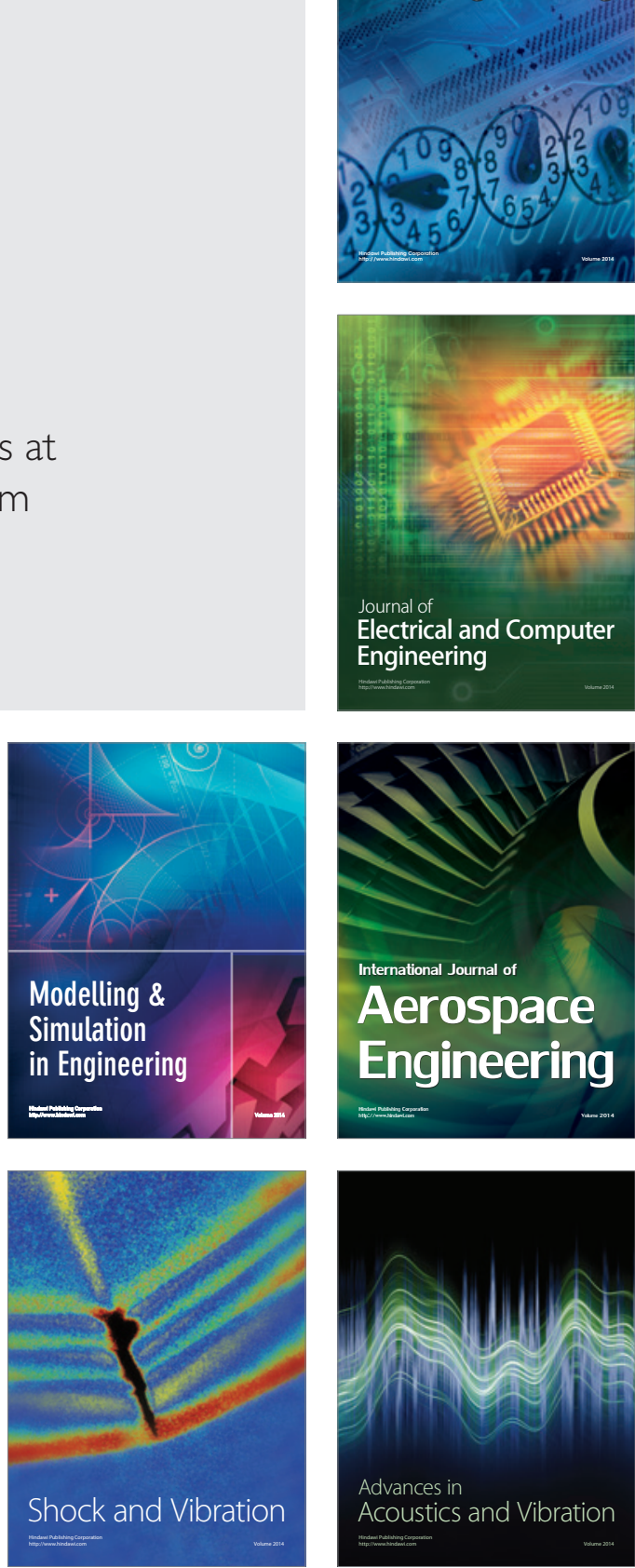